\title{
Education for Sustainable Development: a Strategic Tool for Quality Improvement of Higher Education
}

\section{Wongpreedee, Kageeporn ${ }^{\mathrm{a}}$; Sinsahuang, Karnitta ${ }^{\mathrm{a}}$; Intanakom, Janjira ${ }^{\mathrm{a}}$;} Tanechpongtam, Wanlaya ${ }^{b}$ and Phansuwan-Pujito, Pansiri ${ }^{b}$

${ }^{a}$ Quality Assurance unit, Office of the President, Srinakharinwirot University, Bangkok 10110, Thailand.

${ }^{\mathrm{b}}$ Division of Academic Affairs, Office of the President, Srinakharinwirot University, Bangkok 10110, Thailand.

\begin{abstract}
It has been long known that quality assurance $(Q A)$ is a system to develop quality standards in Thailand. However, it is not easy to implement the concept throughout a whole organization, for example, to include in a university, faculty members, program specifications, management team, and so on. This paper is to explain a case of strategic management of quality assurance using education for sustainable development (ESD) in the university with social enterprise concept. An example of the university with the mission statement of "to serve society" can drawn more attention using ESD concept to faculty in stead of QA regulation concept. The conceptual framework of the implementation was shown how QA can be developed in curriculum embedding with an ESD concept.
\end{abstract}

Keywords: education for sustainable development; quality assurance; higher education, education strategic, social entreprise 


\section{Introduction}

Quality assurance concept was originally driven by industry sectors for productivity and production improvement. Quality in higher education is a prime criteria in global competitiveness for economic growth in the so called knowledge economy. The education system in Thailand was reformed in 1999 with the objective of quality improvement system (Ajpru 2014). It has been known that quality assurance has used for education management driving by the Office for National Education Standards and Quality Assessment, public organization, (ONESQA) and office of higher education commission (OHEC), Ministry of Education in Thailand. Quality in education was applied to university in Thailand both internal quality assessment (IQA) and external quality assessment (EQA). The main goal is to make sure that universities manage the education to students with qualities. Moreover, the other goals are to provide education services to their own communities. Each university has its mission statement to drive the management for its own identity. The mission of an quality assurance method is to improve the quality of teaching and learning process, facilities and infrastructures, well program specification and so on. The key is to meet the success of graduates careers.

After the implementation for decade, the results of education reforms in Thailand have not met the target goals of quality assurance (ONEC, 2005). The new topic are superimposed by several organizations and projects, including the United Nations Decade of Education for Sustainable Development (UN DESD). It was proclaimed by the UN General Assembly as a ten-year period for education action, beginning on January 1st, 2005, with UNESCO designated as the lead agency of Education for sustainability development (ESD). Therefore, the questions come to how to improve the old issue of QA management an how to integrate with an ESD concept together. The goal is to achieve student quality meeting industry expectation. Therefore, this paper aims to identify the root cause of QA management to meet graduate attributes. The samples were shown using the case from university A with the mission stamen of social enterprise concept.

\section{Methodology}

This discussion of the following contents is devided into two sections to discuss an eduation management in university A (Unit A). The first section is to analyze the QA stystem of university A. The following section will show the comparision data of national criteria/indicator measurement from both IQA and EQA. A function expression is displayed. The survey data of indicators relating to mission of university A was shown. The second section is to clarify the conceptual framework of ESD in QA systems: The discussion will be shown how university A using ESD as a strategic tool for quality improvement. 
Wongpreedee K.; Sinsahuang K.; Intanakom, J.; Tanechpongtamb, W. ; Phansuwan-Pujito, P.

\section{Results and discussion}

\subsection{Criteria of QA systems}

Before 2015, QA systems of Unit A use the national criteria/indicator measured by both IQA and EQA as in the faculty and university level. In addition, the university was developed the criteria at a department level of assessment. The score of assessments were correlated among department, faculty, and university criteria which indicator scores can be formulated as following:

Score function of IQA and EQA is expressed as

$$
\mathrm{Y}=\mathrm{f}(\mathrm{F}, \mathrm{R}, \mathrm{S}, \mathrm{Q})
$$

Where $\mathrm{Y}=$ score output,

$$
\begin{aligned}
& \mathrm{F}=\text { Faculty profiles, } \\
& \mathrm{R}=\text { Research papers, } \\
& \mathrm{S}=\text { student performance, } \\
& \mathrm{Q}=\text { qualitative scores in any aspects of process measurement (PDCA) }
\end{aligned}
$$

Score function of Unit A is expressed as

$$
\mathrm{Y}=\mathrm{f}(\mathrm{F}, \mathrm{R}, \mathrm{S}, \mathrm{O}, \mathrm{Q})
$$

Where $\mathrm{Y}=$ score output,

$$
\begin{aligned}
& \mathrm{F}=\text { Faculty profiles, } \\
& \mathrm{R}=\text { Research papers, } \\
& \mathrm{S}=\text { student performance, } \\
& \mathrm{O}=\text { Others such as academic service and management } \\
& \mathrm{Q}=\text { qualitative scores in any aspects of process measurement (PDCA) }
\end{aligned}
$$

From the equation above, various QA systems of EQA, IQA and Unit A were calculated and analyzed in Table 1 . The indicators of each system are measured by qualitative/quantitative methods as shown in $67 \%$ of Unit, $78 \%$ of EQA, and $86 \%$ of IQA based on qualitative assessment. Note that the score of F,R,S,O are from quantitative output data and $\mathrm{Q}$ score is from the qualitative obtaining from PDCA measurement. These indicators of each criteria are from EQA at 18 indicators, IQA at 22 indicators, and Unit A at 21 indicators as displayed in Figure 1. 
Table 1. The percentage of indicators categorized by qualitative/quantitative methods

\begin{tabular}{c|c|c|c|c|c|c}
\hline \multirow{2}{*}{ Catagories } & \multicolumn{3}{|c|}{ Qualitative (per indicator) } & \multicolumn{3}{c}{ Quanltitative (per indicator) } \\
\cline { 2 - 7 } & EQA & IQA & Unit A & EQA & IQA & Unit A \\
\hline Percentage & $78 \%$ & $86 \%$ & $67 \%$ & $22 \%$ & $14 \%$ & $33 \%$
\end{tabular}

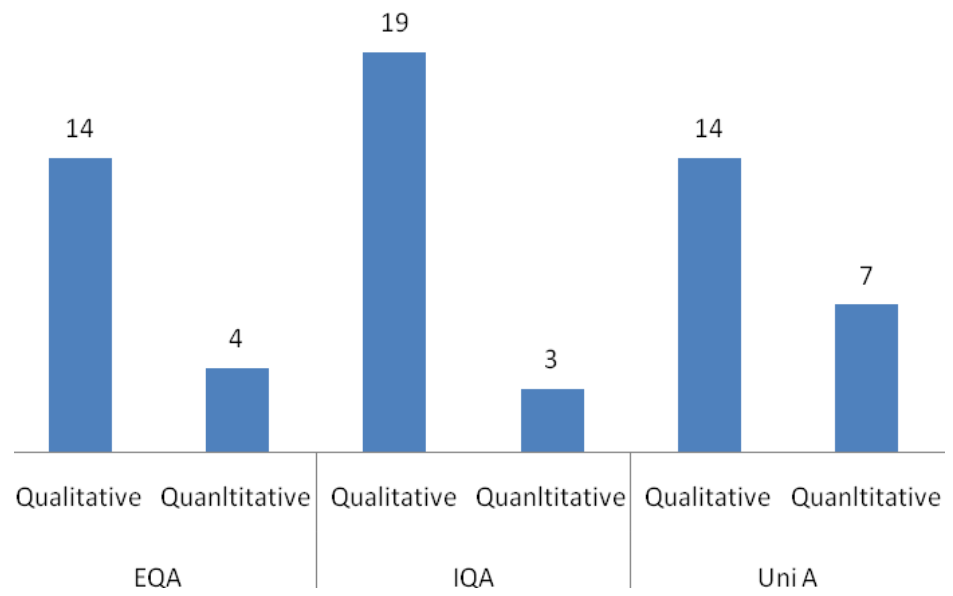

Figure 1. Sum of indicators measuring qualitative/quantitative system in each audit system

According to score functions [1] and [2], the results revealed a high percentage of indicators in the qualitative score "Q" as shown in Tables 1 and 2. Therefore, the score assessment was relied on for assessor judgements. It should also be noted that there are various dimensions of catagories in qualitative scores such as curriculum, academic service, art and culture, management, infrastructure, research, students and faculty. The survey asked for opinions from assessors and faculty members on how well the indicators correlated between Unit A, IQA and, EQA. The results showed that 7 out of 21 of Unit A indicators ( 3 out of 7 indicators from quantitative indicators) have less confidence in assessment correlation of diffferent levels (less than 3.75 out of 5). They also believe that the indicators are not suitable for measuring statements on Unit A's mission, even though the indicators major role is to accomplish the mission of the university, which is "academic service of serving society". This might suggest that education reforms in Thailand have not met the target goals of quality assurance due to the assessment systems and assessors. Regarding issues of development concerning faculty members qualifications and education systems, it should be noted that quality improvement was a barrier by due to the focus of quality assessment rather than working processes to improve the quality standards. 
Table 2. Categories of indicators

\begin{tabular}{l|c|c|c|c|c|c}
\hline \multirow{2}{*}{\multicolumn{1}{c|}{ Categories }} & \multicolumn{3}{|c|}{ Qualitative (per indicator) } & \multicolumn{3}{c}{ Quantitative (per indicator) } \\
\cline { 2 - 7 } & EQA & IQA & Unit A & EQA & IQA & Unit A \\
\hline Curriculum & & 4 & 5 & & & \\
Academic service & 2 & 2 & 1 & & & 2 \\
Art \& culture & 2 & 1 & 1 & & & \\
Management & 7 & 6 & 5 & & & 1 \\
Infrastructure & 1 & 1 & & & & \\
Research & 2 & 2 & 2 & 1 & 1 & 2 \\
Student & & 1 & & 2 & & \\
Faculty & 14 & 19 & 14 & 4 & 3 & 7 \\
\hline
\end{tabular}

\subsection{Conceptual framework of system A}

The development of higher education, in particular the development of new curriculums, are designed according to the policies and needs of the country and sustainability of global issues. This challenges University A to meet its mission statement of social enterprise (SE), "to serve society", in a rapidly changing global environment.

Since the success of QA tools relating to national policy cannot enforce the SE concept from top down, indicated in the left of Figure 2, the university has supported academic service activities on the SE theme. The activities were widespread among faculty members to integrate with the classroom. However, the characteristics of graduates are not embedded in social entreprise. The proposed ESD driven model shown in Figure 2 on the right is depicted as a bottom up model. The key is to use ESD as a strategic tool for quality improvement of universities in social enterprise. This is also shown in the report from Holm showing the clear connection between QA and ESD (Holm, 2015). The short survey after implementation of an ESD seminar shows that the directors of curriculum want to set up the competency with stakeholders. They believe that development with stakeholders will help the modified curriculum achieve greater quality and sustainability. The competency of Unit A students were drawn to communication, social responsibility, and problem solving with ESD in certain elements. Some examples of curriculum building to the economic scale of SMEs are entrepreneurism in education (Wongpreedee, 2015), brand concepts in SE (Virutamasen, 2015) and so on. Such strategies include education criteria adjustment and the improvement of communication between public and private sectors for further sustainable development with stakeholders. 


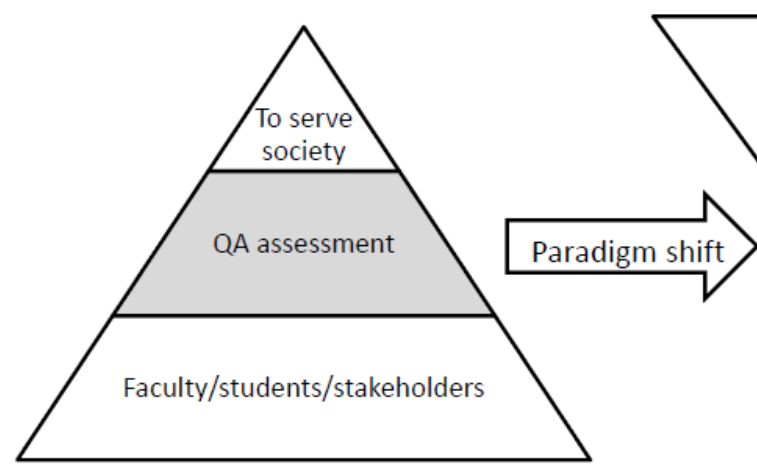

QA tools relating to national policy
Program specifications/ competency/graduate attributes
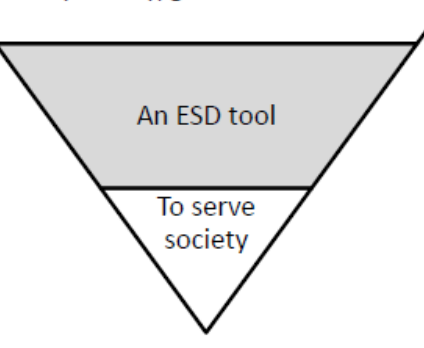

ESD tools embedding in QA

Figure 2. Schematic of conceptual framework of management tool to meet the mission statement

\section{Conclusion}

Thailand has focused on higher education in developing new curriculums that meet academic clusters identified by educational policies and strategies of the country. Quality assurance means policies and strategies to improve the quality standard. This paper suggests the bottom-up ESD-drive model to enhance education quality and the capacity for further sustainable development. In particular, university A with the mission statement of SE could use ESD as a strategic tool for quality improvement systems.

\section{Acknowledgements}

The authors would like to thank Dr.Porngarm Virutamasen for fruitful discussion. Authors would also like to acknowledge the internal funding support provided by Srinakharinwirot University.

\section{References}

Ajpru, H., Wongwanich, S. \& Khaikleng, P.(2014) Design of Educational Quality Assurance System for Driving Policy of Educational Reform in Thailand: Theory-based Evaluation Procedia - Social and Behavioral Sciences 116, 1416 - 1422

Holm, T., Sammalisto, K., Vuorisalo,T. (2015) Education for sustainable development and quality assurance in universities in China and the Nordic countries: a comparative study, Journal of Cleaner Production, 107, 529-537 
Wongpreedee K.; Sinsahuang K.; Intanakom, J.; Tanechpongtamb, W. ; Phansuwan-Pujito, P.

ONEC. (2005). National Education Act of B.E.2542(1999). [Online] Available from: http://mc.ac.th [2010, December 7]

Wongpreedee,K, Kiratisin, A, Virutamasen,P. (2015) Entrepreneurial Mindsets for Innovative Brand Development: Case Studies in Jewellery Education, Procedia - Social and Behavioral Sciences, 195 , 2236-2241

Virutamasen,P., Wongpreedee,K, Kumnungwut, W (2015) Strengthen Brand Association through SE: Institutional Theory Revisited, Procedia - Social and Behavioral Sciences, 195, 192-196 